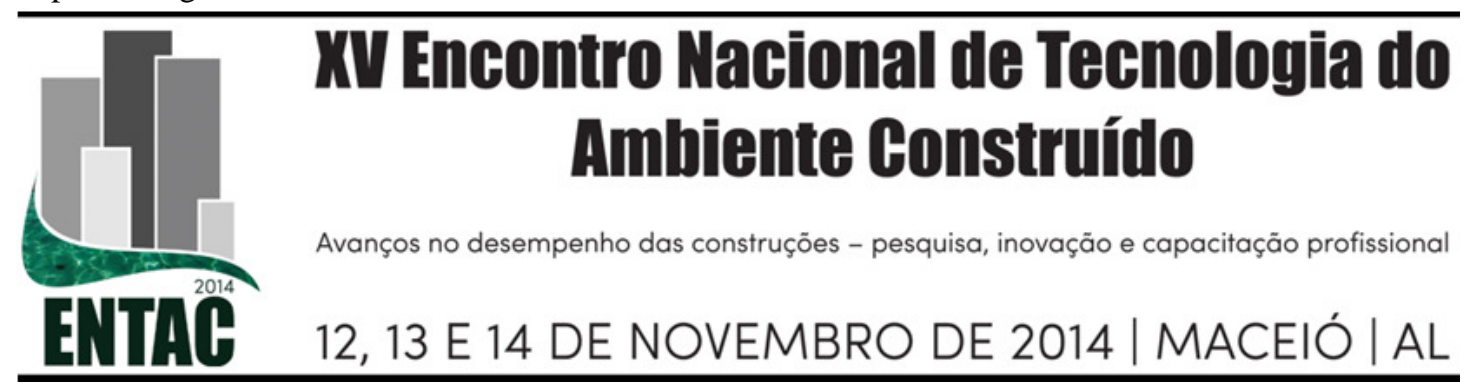

\title{
DESEMPENHO TÉRMICO DE UM AMBIENTE CORPORATIVO NATURALMENTE VENTILADO EM FLORIANÓPOLIS, SC
}

\author{
JEFFE, Ana Paula Magalhães (1); Westphal, Fernando Simon (2) \\ (1) Universidade Federal de Santa Catarina, e-mail: apjeffe@ hotmail.com (2) Universidade Federal de \\ Santa Catarina, e-mail: fernandosw@arq.ufsc.br
}

\begin{abstract}
RESUMO
Este trabalho tem como objetivo geral avaliar o desempenho térmico de um ambiente corporativo em um edifício comercial na cidade de Florianópolis- SC, frente a diferentes estratégias de controle e de setpoint de disponibilidade da ventilação natural, a fim de verificar qual o potencial de aproveitamento desta estratégia, caso o modelo adaptativo considerasse limites de entalpia. A pesquisa foi realizada em nível de mestrado, em desenvolvimento, por meio de um estudo de caso de caráter exploratório. Para avaliação do desempenho térmico foi utilizado o software de simulação computacional EnergyPlus. Como indicador de desempenho foi considerado o número de horas de conforto ao longo do ano. A análise do conforto térmico foi realizada com base no modelo adaptativo da ASHRAE Standard 55/2010. Diferentes alternativas foram simuladas para análise dos efeitos da aplicação de diferentes estratégias de controle e de setpoint (limites) de disponibilidade de ventilação natural. Consideraram-se três limites diferentes de entalpia, baseados na carta psicrométrica e nos valores médios de umidade relativa externa: $55.000 \mathrm{~J} / \mathrm{kg}_{\mathrm{da}}$, $60.000 \mathrm{~J} / \mathrm{kg}_{\mathrm{da}}$ e $65.000 \mathrm{~J} / \mathrm{kg}_{\mathrm{da}}$. De acordo com as alternativas simuladas foi possível observar uma redução do potencial de ventilação natural e de horas de conforto, quando os limites de disponibilidade de ventilação foram estabelecidos por entalpia.
\end{abstract}

Palavras-chave: Ventilação natural, Modelo adaptativo, Simulação Computacional.

\begin{abstract}
The general aim of this study is to evaluate the thermal performance of an office in a business building in Florianopolis-SC, considering the setpoint control strategies for natural ventilation. The following research is part of a master's study being developed in exploratory study. The EnergyPlus software was used to evaluate the thermal performance. As performance indicator the number of comfort hours along the year was considered. The thermal comfort evaluation was measured according to the adaptive model of thermal comfort ASHRAE Standard 55/2010. Several alternatives were simulated to the analysis of the effects of the different setpoint control strategies for natural ventilation in order to evaluate the potential of natural ventilation when using the enthalpy. Three different limits of enthalpy were used based on the Psychometric chart and the average values of external relativity humidity: $55.000 \mathrm{~J} / \mathrm{kg}_{d a}, 60.000 \mathrm{~J} / \mathrm{kg}_{d a} e$ $65.000 \mathrm{~J} / \mathrm{kg}_{\mathrm{da}}$. Accordingly to the options simulated, a valuable decrease in the potential of natural ventilation as well as in the number of comfort hours were noticed when the available ventilation was done through enthalpy
\end{abstract}

Keywords: Natural ventilation, adaptive model, computer simulation

\section{INTRODUÇÃO}

A ventilação natural é uma estratégia importante, principalmente em países de clima quente como o Brasil tanto para o conforto térmico, como para a diminuição do consumo de energia e do uso de ar-condicionado. Considerando ambientes naturalmente 
ventilados, o modelo adaptativo de análise de conforto térmico é baseado na hipótese de que o ser humano tem a tendência natural a se adaptar a diferentes condições ambientais. De acordo com Nicol e Humphreys (2002) o princípio adaptativo considera que se uma mudança ocorre proporcionando desconforto no ser humano, este reage de forma a tentar restaurar novamente o seu conforto.

A norma ASHRAE Standard 55 Environmental Conditions for Human Occupancy adota o princípio adaptativo para análise de ambientes naturalmente ventilados. Este método utiliza-se da temperatura operativa como indicadora de conforto, e define uma temperatura de conforto (temperatura neutra). A norma define faixas de conforto em relação à temperatura neutra, para índices de $90 \%$ e $80 \%$ de pessoas com aceitabilidade às temperaturas de conforto estabelecidas pelo modelo (Figura 1).

\section{Figura 1 - Gráfico das faixas de conforto pelo modelo adaptativo}

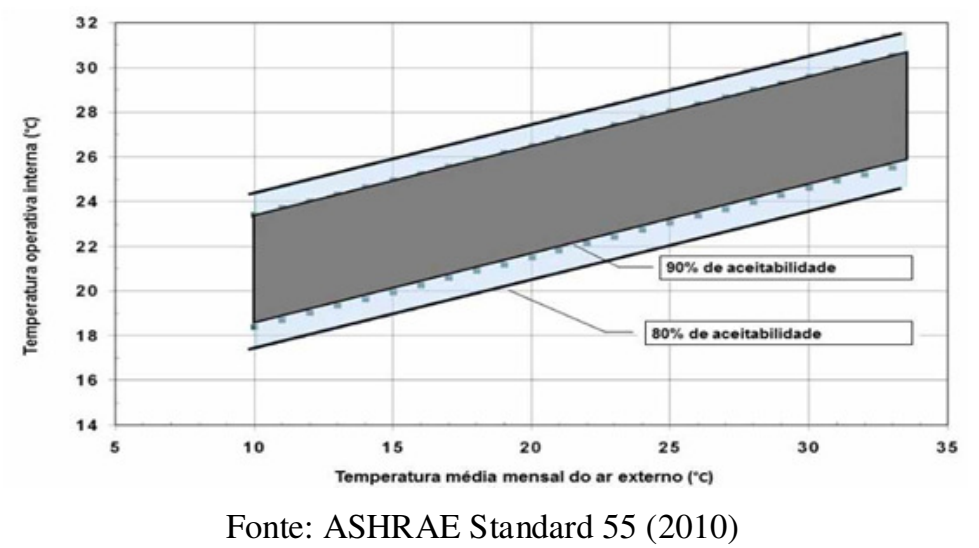

No entanto, de acordo com Halawa e Van Hoof (2012) existem inúmeras questões acerca da abordagem adaptativa, em particular pelo fato de não levar em consideração o efeito de algumas das variáveis presentes nos fatores convencionais de conforto térmico, como a influência da umidade relativa e da velocidade do ar.

Segundo Nicol (2004) na aplicação da abordagem adaptativa de conforto térmico em climas quentes e úmidos, as pessoas desejam uma temperatura de conforto mais baixa se a umidade é alta (UR > 75\%), onde o efeito principal da umidade relativa (ou a pressão do vapor de água) é o de reduzir a largura das faixas da zona de conforto. Portanto caso houvesse um limite de umidade relativa de $70 \%$ por exemplo, para este tipo de clima, haveria a diminuição da faixa de temperatura aceitável.

Estabelecer um limite, controle da umidade para os ambientes é fator importante para a saúde e conforto dos ocupantes. Altas umidades podem causar condensação aumentando a degradação de materiais e contaminação biológica. Projetistas costumam dimensionar os sistemas HVAC com limite de $65 \%$ de umidade relativa, para desumidificar os ambientes.

Os resultados da pesquisa de Rupp e Ghisi (2014) mostram por meio das correlações entre o número de horas de ar condicionado e uso das variáveis ambientais, que o uso de ar-condicionado é muito dependente da temperatura do ar e da umidade absoluta. A aplicação do modelo adaptativo da norma ASHRAE Standard 55/2010 para espaços ventilados naturalmente, levou a pouco uso de ar-condicionado em dezembro (verão), o que não é consistente com o padrão de uso de ar-condicionado observado em Florianópolis. 
Este experimento foi realizado em nível de mestrado, ainda em desenvolvimento, por meio de um estudo de caso de caráter exploratório. Esta pesquisa faz parte de uma etapa parcial da exploração de um modelo de análise de conforto, para avaliar a aplicação da estratégia passiva de ventilação natural em conjunto com o condicionamento artificial, em prédios hospitalares.

\section{OBJETIVOS}

O objetivo deste trabalho é avaliar o desempenho térmico de duas salas comerciais naturalmente ventiladas num edifício de escritórios na cidade de Florianópolis- SC, a fim de verificar qual o potencial de aproveitamento da ventilação natural, caso o modelo adaptativo considerasse limites de entalpia.

\section{MÉTODO}

O método consiste na simulação computacional por meio do software EnergyPlus, para verificação dos efeitos da aplicação de diferentes estratégias de controle e de setpoint (limites) de disponibilidade de ventilação natural. Para a simulação computacional foi utilizado o arquivo climático do tipo "TRY” para a cidade de Florianópolis.

Para a análise de desempenho nas zonas térmicas foi calculado o número de horas em conforto térmico para um ano inteiro, considerando apenas as horas ocupadas em dias úteis, num total de 2.610 horas por ano. Foram obtidos os percentuais de horas de conforto dentro das faixas de temperaturas operativas para os índices de $80 \%$ e $90 \%$ de pessoas satisfeitas, estabelecidos pelo modelo adaptativo da norma ASHRAE Standard $55 / 2010$.

\subsection{Descrição do modelo}

O objeto de estudo desta pesquisa constitui-se em um ambiente corporativo localizado no oitavo pavimento de um edifício comercial, na cidade de Florianópolis-SC. Segundo a NBR 15220 (ABNT, 2005), a cidade encontra-se localizada na zona bioclimática três.

As dimensões totais do ambiente a ser analisado são: largura $10,60 \mathrm{~m}$, comprimento $8,50 \mathrm{~m}$, com área total de $90 \mathrm{~m}^{2}$ e pé-direito de $2,75 \mathrm{~m}$ (Figura 2). O ambiente é composto de duas salas de $45,50 \mathrm{~m}^{2}$ contíguas e conectado por uma porta. Para as simulações, cada uma destas salas foi considerada como uma zona a ser avaliada. Foi elaborado um modelo 3D do objeto de estudo (Figura 3).

Figura 2 - Planta baixa do ambiente

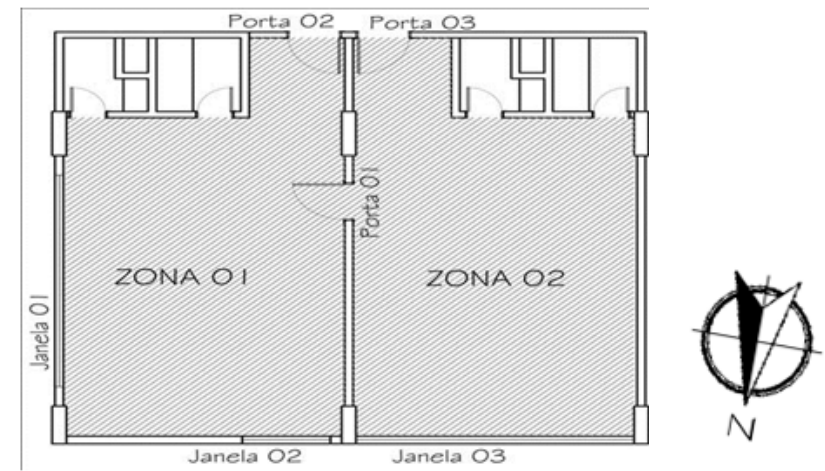

Fonte: Autor (2013). 
O objeto de estudo possui janelas em alumínio e vidro simples $6 \mathrm{~mm}$ com folhas fixas e folhas de correr, e portas em madeira com uma folha de abrir e dimensões de 0,80m de largura por $2,10 \mathrm{~m}$ de altura. $\mathrm{Na}$ zona 1 há a janela 01 situada na fachada leste com área de $2,85 \mathrm{~m}^{2}$ de abertura e $7,85 \mathrm{~m}^{2}$ fixa, na fachada norte está a janela 02 com área de $0,87 \mathrm{~m}^{2}$ de abertura e $2,63 \mathrm{~m}^{2}$ fixa. Na zona 2 há a janela 03 na fachada norte com área de $2,50 \mathrm{~m}^{2}$ de abertura e de $7,5 \mathrm{~m}^{2}$ de área fixa. A porta 01 faz a conexão entre as zonas, sendo que cada uma das zonas possui uma porta (portas 02 e 03 ) que ás conecta a um corredor.

\section{Figura 3 - Modelo 3D do objeto de estudo}

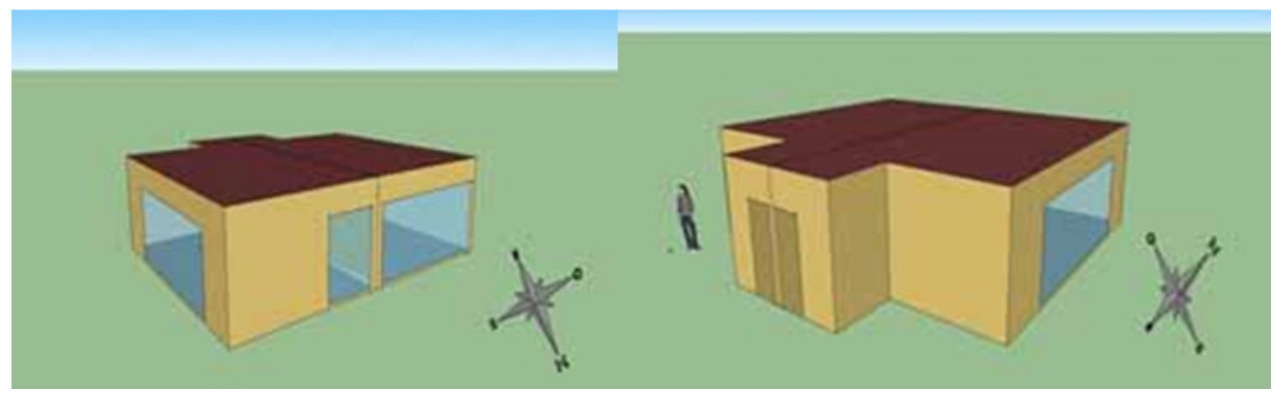

Fonte: Autor (2013).

As propriedades dos materiais construtivos foram consideradas com base na norma NBR15220 (ABNT, 2005). As horas de ocupação, as cargas internas e as propriedades dos materiais são apresentadas no Quadro 1.

\section{Quadro 1 - Dados de ocupação, cargas internas e materiais construtivos}

\begin{tabular}{|c|c|c|}
\hline Ocupação & Cargas Internas & Materiais construtivos \\
\hline $\begin{array}{l}\text { Período de ocupação } \\
\text { Dias úteis: } 8 \mathrm{~h} \text { às } 12 \mathrm{~h} 30 \\
\text { 14h às } 18 \mathrm{~h} \\
\text { Finais de semana: Sem } \\
\text { ocupação }\end{array}$ & $\begin{array}{l}\text { Iluminação } \\
320 \mathrm{~W} \text { por zona }\end{array}$ & 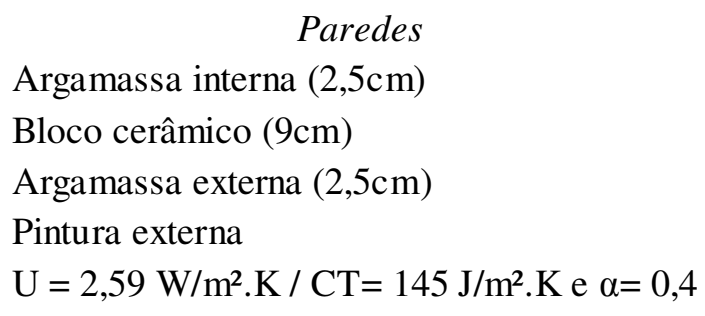 \\
\hline $\begin{array}{l}\text { Número de pessoas } \\
\text { Zona 1: } 4 \text { pessoas } \\
\text { Zona 2: } 6 \text { pessoas }\end{array}$ & $\begin{array}{l}\text { Equipamentos } \\
\text { Zona 1: } 800 \mathrm{~W} \\
\text { Zona 2: } 1200 \mathrm{~W}\end{array}$ & $\begin{array}{l}\text { Cobertura } \\
\text { Laje armada em blocos cerâmicos, com } \\
\text { vigotas em concreto armado. } \\
\text { Espessura total } 12 \mathrm{~cm} \text {, rebocada. } \\
\mathrm{U}=2,95 \mathrm{~W} / \mathrm{m}^{2} . \mathrm{K} / \mathrm{CT}=167 \mathrm{~J} / \mathrm{m}^{2} . \mathrm{K} / \alpha=0,2\end{array}$ \\
\hline
\end{tabular}

Fonte: Autor (2013)

\subsection{Alternativas simuladas}

Foram simuladas diferentes estratégias de controle de disponibilidade de ventilação natural nas horas ocupadas, com a finalidade de testar diferentes setpoints de temperatura em conjunto com setpoints de entalpia do ar externo.

O software EnergyPlus considera, no controle por temperatura, que as aberturas são acionadas para permitir a ventilação natural quando a temperatura interna do ar na zona é igual ou superior a temperatura do ar externo, e se a temperatura interna do ar na zona 
é igual ou superior a temperatura de setpoint. No controle por entalpia, o software considera que as aberturas são acionadas quando a entalpia do ar na zona é maior que a externa, além de verificar se a temperatura da zona é maior que a temperatura de setpoint.

Para verificar o potencial da ventilação natural na inserção da variável entalpia, utilizouse do campo que permite estipular a ocorrência da disponibilidade da ventilação natural. Para isto considerou-se três limites diferentes de entalpia, baseados na carta psicrométrica e nos valores médios de umidade relativa externa: $55.000 \mathrm{~J} / \mathrm{kg}_{\mathrm{da}}$ (Joules por quilograma de ar seco), $60.000 \mathrm{~J} / \mathrm{kg}_{\mathrm{da}}$ e $65.000 \mathrm{~J} / \mathrm{kg}_{\mathrm{da}}$. Na Figura 4 é apresentada a estrutura das alternativas simuladas.

Para o setpoint de temperatura foram consideradas as faixas de limite de temperatura operativa de conforto, segundo modelo adaptativo presente na norma ASHRAE Standard 55/2010. Utilizaram-se como referência as temperaturas médias da cidade de Florianópolis para o ano inteiro. A partir da temperatura média foram definidos os limites máximos de temperatura operativa para $90 \%$ e $80 \%$ de pessoas satisfeitas. Embora o EnergyPlus permita apenas a temperatura do ar como variável de controle da ventilação natural, esses limites de temperatura operativa foram adotados como setpoint de temperatura para "acionamento" da ventilação natural.

Figura 4 - Estrutura das alternativas simuladas

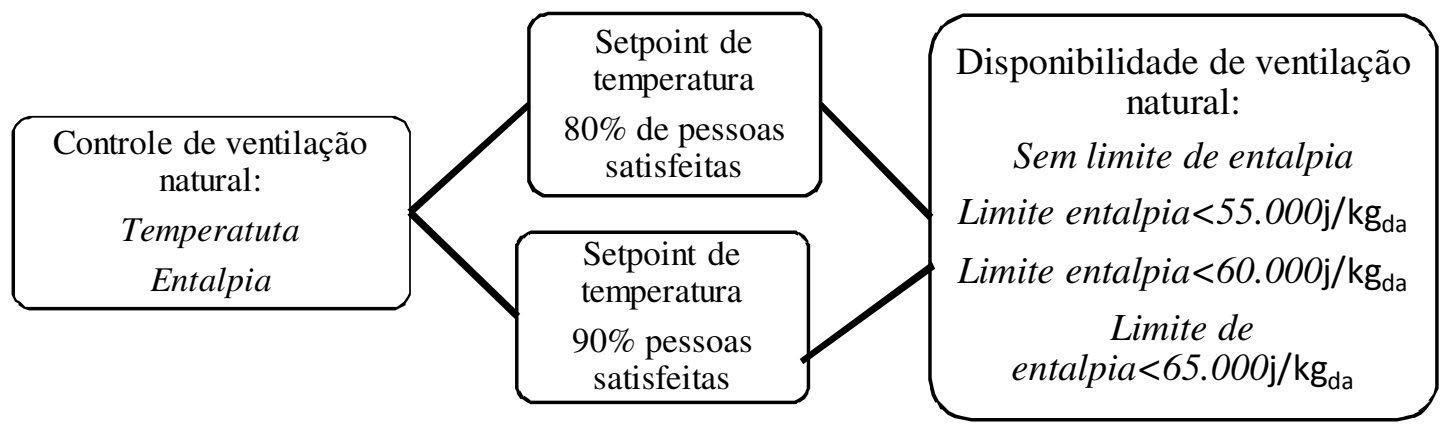

Fonte: Autor (2014)

\section{RESULTADOS E DISCUSSÕES}

Em todas as alternativas simuladas observam-se algumas horas a mais de conforto na zona 1 do que na zona 2 . A zona 1 possui duas janelas em orientações diferentes, a sua porta de acesso e a porta contígua a zona 2, possibilitando mais trocas de ar e a ventilação cruzada. O potencial do uso da ventilação natural é maior para a Zona 1. A zona 2 possui apenas janela em uma orientação, o que apenas permite a ventilação simples, além da porta de acesso a zona e a porta contígua a zona 1, o que reduz o potencial do uso da ventilação natural para esta zona.

No entanto, a orientação das janelas tanto da zona 1 quanto da zona 2 não estão voltadas para a orientação dos ventos predominantes, que são de Norte e Nordeste (Figura 5), o que também dificulta as trocas de ar e o potencial da ventilação natural. 
Figura 5 - Frequência de ocorrência dos ventos para Florianópolis

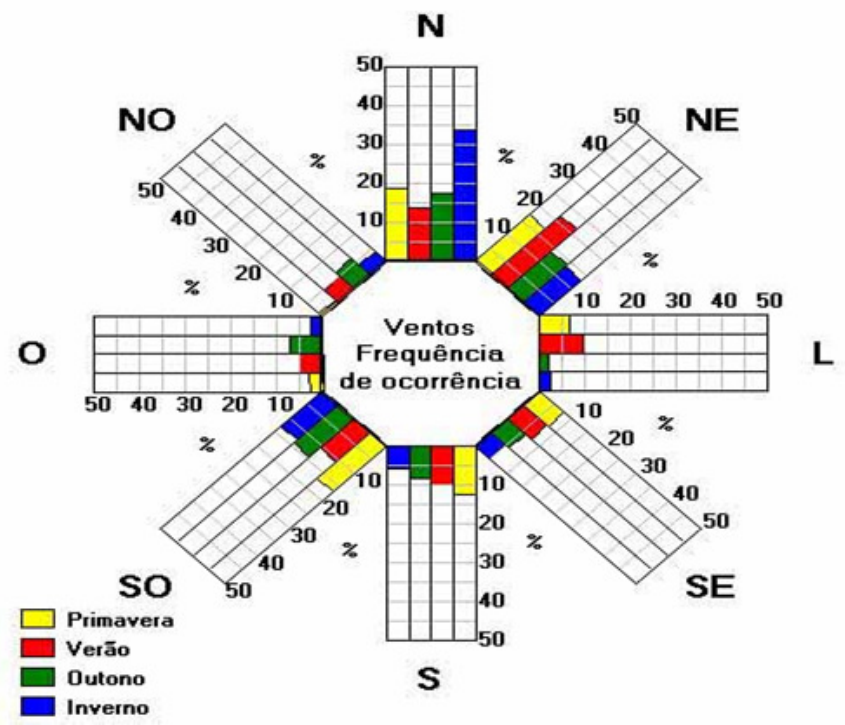

Fonte: Software Sol-Ar 6.2(2014)

Os gráficos à esquerda correspondem aos casos simulados com controle da ventilação apenas por temperatura do ar. Os gráficos à direita consideram o controle da ventilação por verificação entre o valor de entalpia do ar interno e externo. Os resultados apresentados nas Figuras 6 e 7 representam os percentuais de horas de conforto obtidos nas diferentes alternativas de setpoint de temperatura para $90 \%$ de aceitabilidade.

As Figuras 8 e 9 apresentam os percentuais de horas de conforto obtidos com os mesmos parâmetros já citados, porém com setpoint de temperatura dentro dos limites de $80 \%$ de aceitabilidade.

Figura 6 - Horas de conforto na faixa de $90 \%$ de pessoas satisfeitas, para setpoint de temperatura no limite de $90 \%$ de aceitabilidade.

Sem controle de entalpia

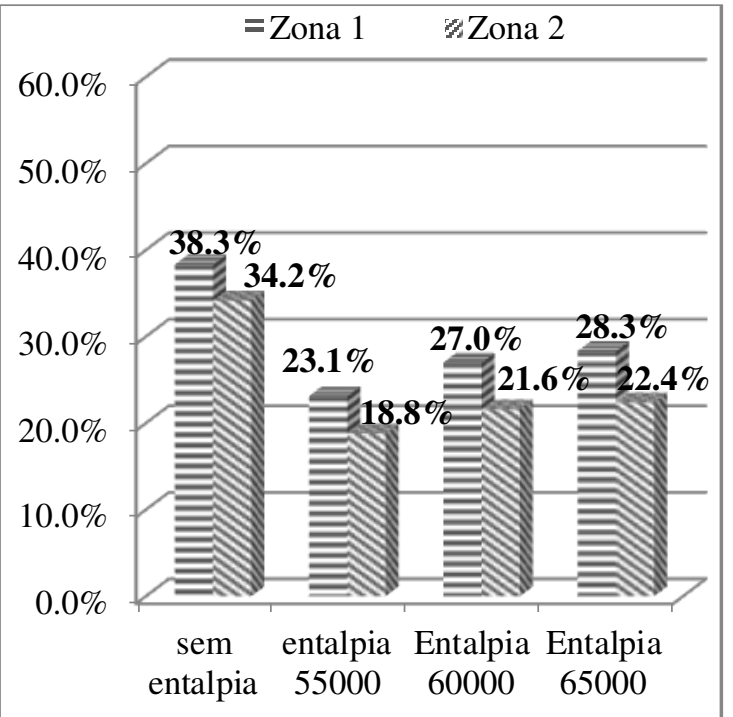

Com controle de entalpia

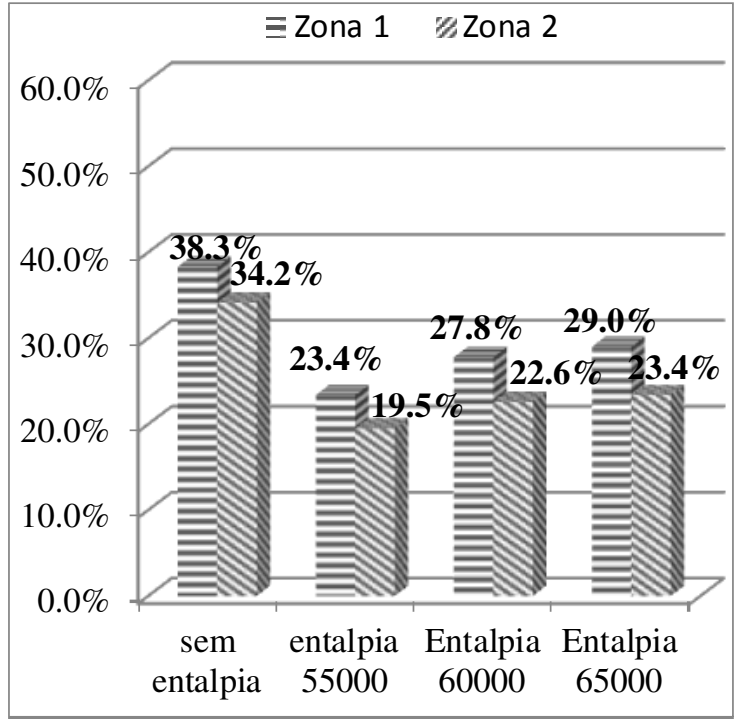

Fonte: Autor (2014) 
De forma geral verificou-se pouca diferença nas horas de conforto entre uma zona e outra quando comparados os resultados obtidos com controle apenas por temperatura e aqueles obtidos com controle por entalpia. O mesmo ocorre com os diferentes setpoint de temperatura utilizados, onde as diferenças de valores de percentuais de horas de conforto são de até $2 \%$. Verifica-se um aumento de até 15,3 pontos percentuais quando se aumenta a faixa de tolerância para a aceitabilidade do ambiente (Figuras 6 e 7).

\section{Figura 7 - Horas de conforto na faixa de $80 \%$ de pessoas satisfeitas, para setpoint de temperatura no limite de $90 \%$ de aceitabilidade.}

Sem controle de entalpia

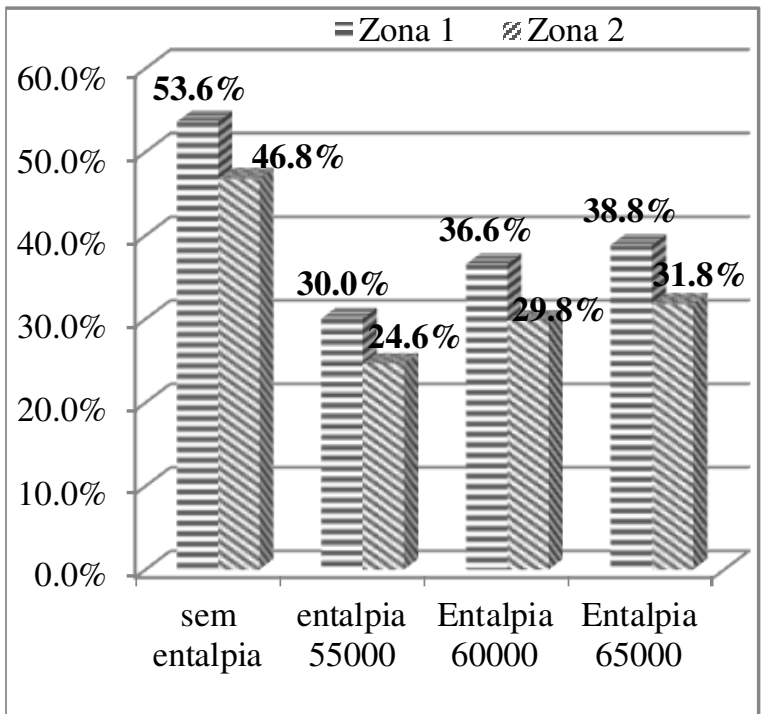

Com controle de entalpia

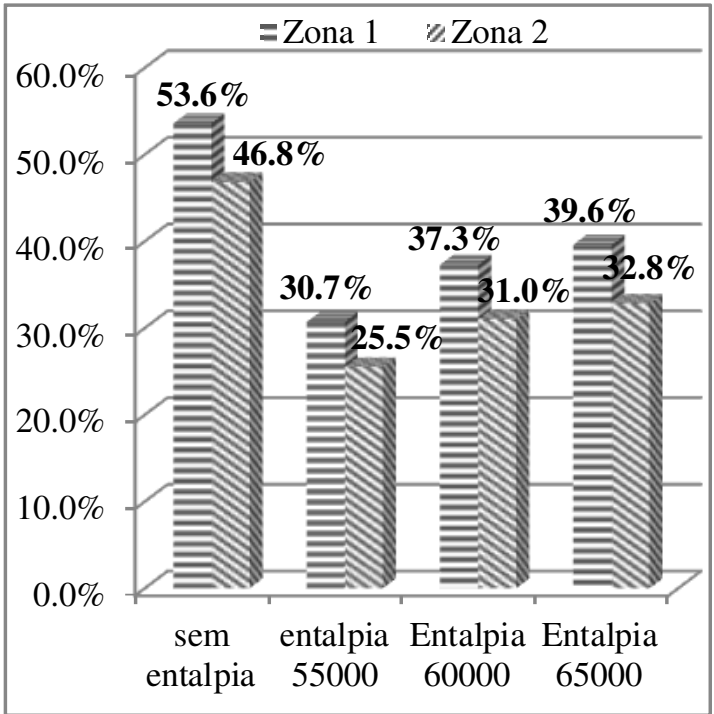

Fonte: Autor (2014)

Por meio da análise dos resultdos, foram encontradas diferenças relevantes no percentual de horas de conforto quando se estabelece um limite de entalpia para aproveitamento da ventilação natural. A redução nas horas de conforto chegou a 20 pontos percentuais quando se analisa a faixa de conforto para $80 \%$ de aceitabilidade (Figuras 8 e 9) e a mudança do controle sem limite de entalpia para o limite de 55.000 $\mathrm{J} / \mathrm{kg}_{\mathrm{da}}$. Aumentando-se a tolerância da entalpia para até $65.000 \mathrm{~J} / \mathrm{kg}_{\mathrm{da}} \mathrm{o}$ aumento nas horas de conforto foi de até 9 pontos percentuais na zona 1.

$\mathrm{Na}$ análise dos resultados do primeiro gráfico da Figura 8, para entalpia em 55.000 $\mathrm{J} / \mathrm{kg}_{\mathrm{da}}$, houve uma redução de $14 \%$ para a zona 1 e $12,8 \%$ para a zona 2 . Para o limite de $60.000 \mathrm{~J} / \mathrm{kg}_{\text {da }}$ houve uma reduçao de horas de $10,3 \%$ na zona 1 e $10,2 \%$ na zona 2 . No limite de $66.000 \mathrm{~K} \mathrm{~J} / \mathrm{kg}_{\mathrm{da}}$ as diferenças ficaram em $9,3 \%$ na zona1 e $9,7 \%$ na zona 2 .

Essa alteração nas horas de conforto devido à imposição de limites de entalpia significa que há uma redução significativa no potencial de aproveitamento da ventilação natural quando se analisa a temperatura do ar externo em conjunto com a umidade relativa. $\mathrm{O}$ limite de entalpia não está previsto no modelo adaptativo da norma ASHRAE Standard $55 / 2010$, e o presente estudo faz essa suposição de forma provocativa para investigar os efeitos na economia de energia com climatização em clima quente e úmido.

Atualmente, o projeto de edifícios corporativos em grandes centros urbanos brasileiros prioriza o uso de condicionamento de ar, em detrimento de estratégias que possam explorar a ventilação natural por mais horas ao longo do ano. No entanto, as simulações 
aqui descritas indicam que considerando a temperatura do ar externo como parâmetro de operação das janelas do edifício, o uso da ventilação natural pode ser explorado por até metade do ano, ou 130 dias úteis. Mas quando se supõe um limite de aproveitamento da ventilação natural apenas para umidades mais baixas (entalpia do ar externo mais baixa), o número de dias equivalentes de uso dessa estratégia cai para até 47 dias, ou seja, o ar-condicionado seria imprescindível em dez meses do ano.

Figura 8 - Horas de conforto na faixa $90 \%$ de pessoas satisfeitas, para setpoint de temperatura no limite de $80 \%$ de aceitabilidade.

Sem controle de entalpia

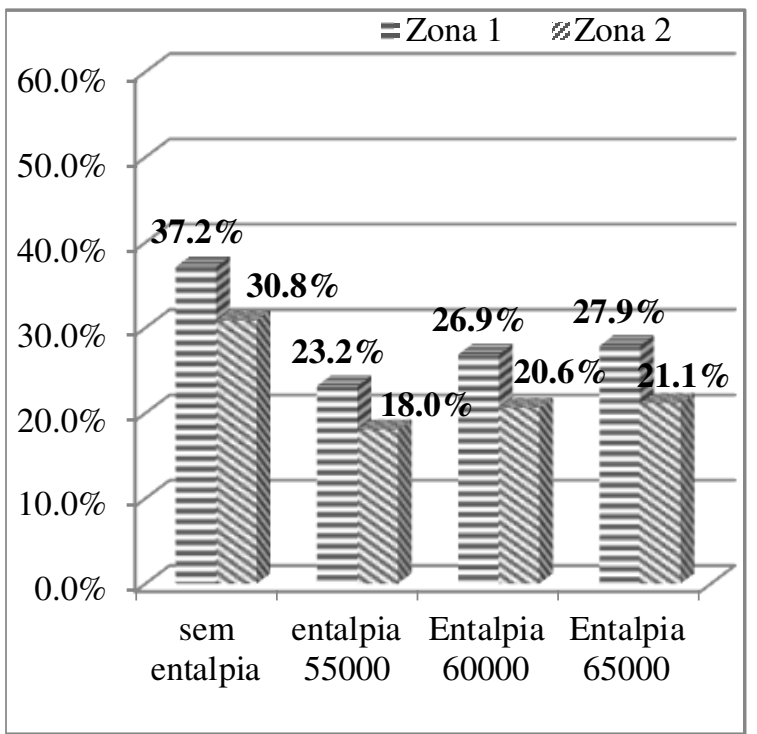

Com controle de entalpia

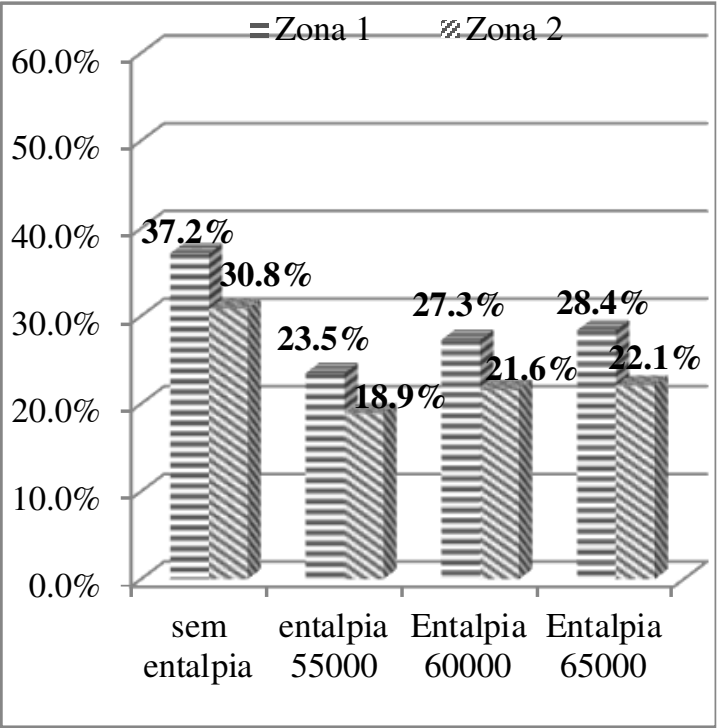

Fonte: Autor (2014)

Figura 9 - Horas de conforto na faixa $80 \%$ de pessoas satisfeitas, para setpoint de temperatura no limite de $80 \%$ de aceitabilidade.

Sem controle de entalpia

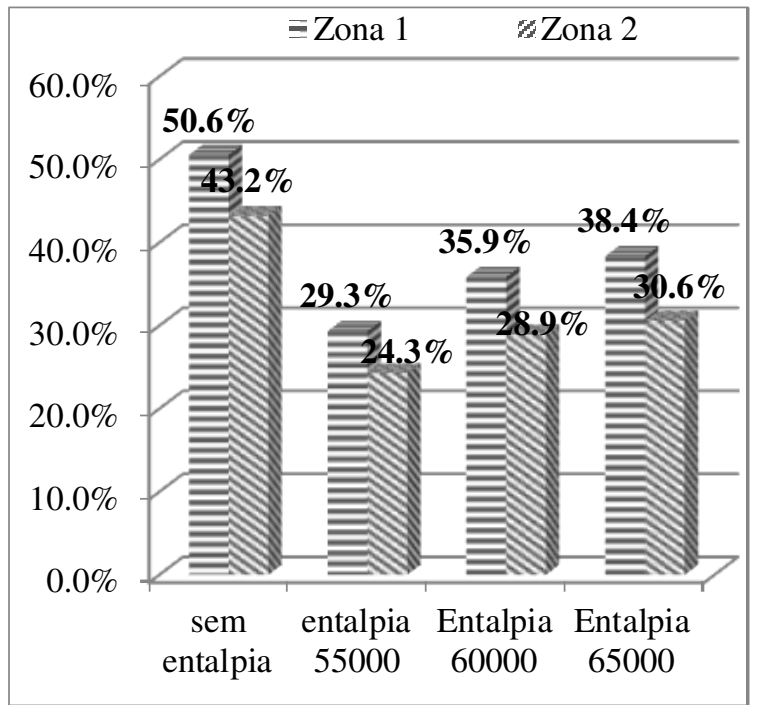

Com controle de entalpia

10.0\%

Fonte: Autor (2014) 
A análise dos resultados mostra que os limites considerados para a variável de entalpia afetam os resultados do desempenho térmico do ambiente avaliado, diminuindo as horas de conforto no ano. Isto ocorre devido ao fato do potencial da ventilação natural como estratégia passiva para perda de calor por convecção, ficar reduzido. Ao colocar o limite de entalpia, elimina-se a ventilação natural nas horas em que a temperatura do ar externo é alta, com uma umidade relativa acima da reta de entalpia, conforme ilustrado na Figura 10.

\section{Figura 10 - Carta psicrométrica indicando limites de entalpia adotados no estudo}

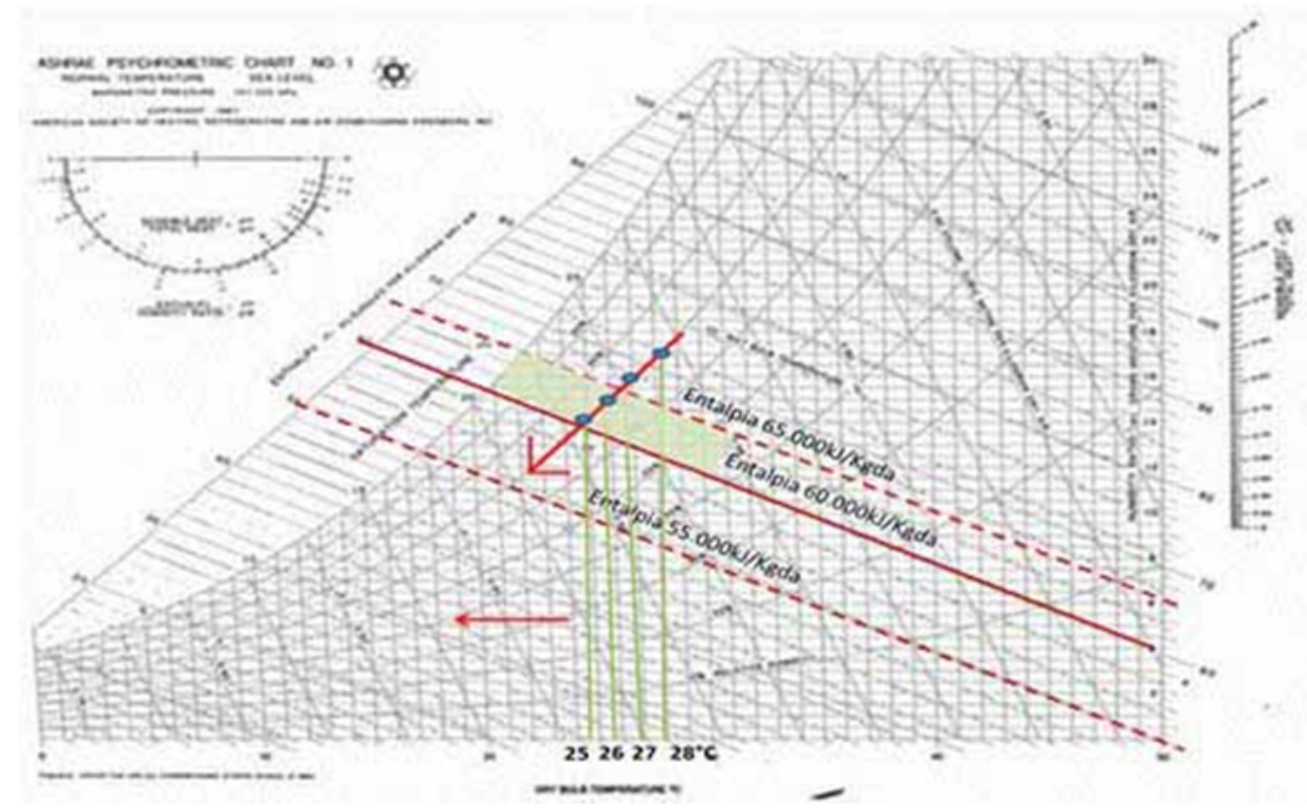

Fonte: ASHRAE 55 - adaptado (2010)

Por exemplo, considerando os resultados descritos anteriormente, a zona 1 possui um potencial de aproveitamento da ventilação natural de até 100 dias no ano, considerando a faixa de conforto para $90 \%$ de aceitabilidade e sem limite de entalpia. Mas quando adiciona-se um limite de $55.000 \mathrm{~J} / \mathrm{kgda}$ para permitir que o ar externo seja admitido por ventilação natural, os dias de conforto com essa estratégia passiva são reduzidos para 60 , ou seja, um corte de mais de um mês.

Pela carta psicrométrica verifica-se que esse limite de entalpia corresponde ao ar na temperatura de bulbo seco (TBS) de $28{ }^{\circ} \mathrm{C}$ e umidade relativa (UR) de $35 \%$; ou TBS de $27{ }^{\circ} \mathrm{C}$ e UR de $40 \%$. Mesmo sendo temperaturas aceitáveis pelo modelo adaptativo, caso houvesse um limite de umidade relativa, nessas condições a ventilação natural não seria suficiente para atendimento do conforto térmico interno.

\section{CONSIDERAÇÕES FINAIS}

Esta pesquisa apresentou uma análise de desempenho térmico de um ambiente corporativo, no uso da estratégia passiva de ventilação natural, por meio da abordagem adaptativa de análise do conforto. Foram simuladas diferentes estratégias de aproveitamento da ventilação natural buscando-se atender a limites de entalpia do ar externo. As simulações foram conduzidas no software EnergyPlus, para arquivo climático da cidade de Florianópolis. 
Verificou-se que na aplicação de limites de entalpia para aproveitamento do ar externo, o potencial da ventilação como estratégia de condicionamento passivo fíca consideravelmente reduzido, diminuindo assim as horas de conforto durante o ano para os ambientes analisados. A redução no potencial do uso da ventilação natural aumenta a necessidade de condicionamento artificial, também aumentando o consumo de energia, fato atualmente comum nos ambientes corporativos em clima quente e úmido.

Ao considerar o limite de entalpia supõe-se que apenas a termperatura de bulbo seco não seria suficiente como parâmetro de análise de conforto pelo modelo adaptativo. De fato, Nicol (2004) demonstra que num clima quente e úmido, com altos índices de umidade relativa, as pessoas preferem temperaturas do ar $1^{\circ} \mathrm{C}$ mais baixas do que em climas secos para sentirem-se confortáveis, reduzindo a faixa de temperaturas de conforto consideradas hoje pelo modelo adaptativo.

No presente trabalho, especulou-se a variação no percentual de horas de conforto simulando-se alguns cenários limites de entalpia do ar externo. A variação no total de horas de conforto dos escritórios simulados foi significativa, atingindo uma redução de até $40 \%$ no período de conforto ao longo do ano, o que representa uma necessidade do ar-condicionado em mais de 200 dias, ou um aproveitamento da ventilação natural em apenas 60 dias (considerando 260 dias úteis no ano).

Mais pesquisas são necessárias para se verificar com mais profundidade os efeitos da umidade na aplicação do modelo adaptativo para análise de conforto térmico nos ambientes, principalmente em climas quentes e úmidos.

Este artigo é parte inicial de uma pesquisa de caráter exploratório, onde se investiga um modelo de conforto térmico que possa ser aplicado para análise em ambientes com sistema de climatização híbrido.

\section{REFERÊNCIAS}

ASHRAE STANDARD 55 - 2010. Thermal Environmental Conditions for Human Occupancy. American Society of Heating, Refrigerating and Air-Conditioning Engineers, Inc. Atlanta, GA, 2010.

ASSOCIAÇÃO BRASILEIRA DE NORMAS TÉCNICAS (ABNT). NBR-15220: Desempenho Térmico de Edificações - Elaboração. Rio de Janeiro, 2005.

HALAWA, E.; VAN HOOF, J. The adaptive approach to thermal comfort: A critical overview. Energy and Buildings, v. 51, p. 101-110, ago. 2012.

NICOL, F. Adaptive thermal comfort standards in the hot-humid tropics. Energy and Buildings, v. 36, n. 7, p. 628-637, 2004.

NICOL, J. F.; HUMPHREYS, M. A. Adaptive thermal comfort and sustainable thermal standards for buildings. Energy and Buildings, v. 34, n. 6, p. 563-572, jul. 2002.

RUPP, R. F.; GHISI, E. What is the most adequate method to assess thermal comfort in hybrid commercial buildings located in hot-humid summer climate? Renewable and Sustainable Energy Reviews, v. 29, p. 449-462, jan. 2014. 